\title{
Um Estudo das Manifestações Patológicas em Vigas e Lajes de Concreto: Edificações da FCT/UNESP
}

\author{
A Study of Pathological Manifestations in Beams and Concrete Slabs: Buildings of \\ FCT/UNESP
}

\section{Cesar Fabiano Fioriti ${ }^{1}$ (Dorcid.org/0000-0001-5461-4495 \\ Maria Paula Hêngling Christófani ${ }^{1}$ (Dorcid.org/0000-0002-4233-6544}

Nayra Yumi Tsutsumoto² (Dorcid.org/0000-0002-8410-0716

Fernando Sérgio Okimoto ${ }^{1}$ (D)orcid.org/0000-0003-1385-8316

${ }^{1}$ Departamento de Planejamento Urbanismo e Ambiente, Faculdade de Ciências e Tecnologia, Universidade Estadual Paulista,
Presidente Prudente, Brasil,
${ }^{2}$ Instituto Federal de Minas Gerais - IFMG, Santa Luzia, Brasil.

E-mail do autor principal: Cesar Fabiano Fioriti fioriti@fct.unesp.br

\section{Resumo}

Este trabalho trata de estudo de caso realizado nas edificações pertencentes à Universidade Estadual Paulista (FCT/UNESP), de Presidente Prudente, em que por meio de inspeção visual foram identificadas as manifestações patológicas existentes nas vigas e lajes de concreto armado. A metodologia envolveu a realização da análise das características das anomalias, bem como sua importância, as causas mais prováveis e as possíveis soluções de reparo. Os problemas detectados que ocorreram com maior incidência nas vigas foram: manchas escuras, lixiviação, corrosão da armadura por esfoliação e corrosão de estribos. Nas lajes os principais problemas acometidos foram: recalque diferencial, fissuras de retração térmica e corrosão de armadura. Foi observado um padrão apresentado no processo de recuperação das estruturas de concreto, no que diz respeito às técnicas de reparo das peças estruturais. E se tratando de fissuras e corrosão das armaduras, pode-se constatar que se não forem obedecidos os critérios para proteção e bom uso das estruturas, é certo que, necessariamente, em qualquer tempo, essa mesma estrutura precisará ser recuperada. Diante do exposto, foi notado que os danos poderiam ter sido minimizados caso houvesse um efetivo controle da qualidade durante o processo construtivo dos sistemas estruturais analisados, aliado a um programa de manutenção preventiva.

Palavras-Chave: Sistemas estruturais; Degradação; Edificações públicas; Concreto armado.

\section{Abstract}


This paper deals with a case study carried out in the buildings belonging to the State University of São Paulo, of Presidente Prudente, in which the pathological manifestations in the beams and slabs of reinforced concrete were identified through visual inspection. The methodology involved the analysis of the characteristics of the anomalies, as well as their importance, the most probable causes and possible repair solutions. The problems detected that occurred with greater incidence in the beams were: dark spots, leaching, corrosion of the reinforcement by exfoliation and corrosion of stirrups. In the slabs the main problems were: differential repression, thermal retraction cracks and reinforcement corrosion. Was observed a pattern presented in the process of recovery of reinforced concrete structures, with respect to the techniques of repair of structural parts. It can be seen that if the criteria for protection and good use of the structures are not obeyed, it is certain that, at any time, this same structure will have to be recovered. It was noted that the damages could have been minimized had there been an effective quality control during the construction process of the analyzed structural systems, together with a preventive maintenance program.

Key-words: Structural systems; Degradation; Public buildings; Concrete.

\section{Introdução}

$\mathrm{Na}$ construção civil a rapidez na execução e o emprego de novas tecnologias são fundamentais para tornar o mercado mais competitivo e possibilitar novos empreendimentos. Inovações e rapidez de execução acarretaram na necessidade de se desenvolver o conhecimento relacionado às estruturas e aos materiais, a fim de proporcionar o avanço das construções. Entretanto, ainda que o investimento em tecnologias relacionadas a essas construções cresceu e evoluiu desde o início das civilizações até os dias atuais, ainda assim, existem sérias limitações e inevitáveis falhas que acabam por prejudicar o desempenho de algumas estruturas. Esses fatores conduzem ao surgimento de manifestações patológicas, que podem ser entendidas como perda ou queda de desempenho de um conjunto ou componente estrutural.

Como a manifestação patológica pode ser influenciada pelo comportamento da estrutura em uso, pelo tempo e pelas condições de exposição, percebe-se, portanto, que há uma forte relação entre a anomalia e desempenho, vida útil e durabilidade da edificação [1].

Em uma sequência temporal do processo patológico podemos distinguir três partes diferenciadas: a origem, a evolução e o resultado final. Para o estudo do processo patológico convém recorrer a esta sequência de modo inverso, onde se observa primeiramente o resultado da anomalia, depois os sintomas, para, seguindo a evolução da mesma, alegar sua origem: a causa. Este processo permitirá estabelecer tanto a estratégia de reparação como a hipótese de prevenção.

Os problemas de deterioração da estrutura e de seus materiais componentes decorrem, em grande parte, de um projeto inadequado e de uma execução mal cuidada, deficiências que ainda se constata serem comuns, provocando a ocorrência de falhas que, fatalmente, resultam na necessidade de recuperação ou de reforço da estrutura [2].

Estudos têm demonstrado que quanto mais cedo se detectar uma anomalia, mais eficiente e menos onerosa será a intervenção. Muitos cuidados são deixados de lado quando se projeta, se constrói ou se utiliza uma edificação, prejudicando a vida útil e o desempenho de sua estrutura [3].

Desta maneira, a maioria das manifestações patológicas poderia ser evitada se houvesse um melhor detalhamento de projeto, tal como a escolha apropriada dos materiais e a correta execução da construção, assim como uma maior preocupação com a realização das intervenções de manutenção nos elementos que compõem as edificações [4]; [5].

O concreto armado é atualmente um material intensamente utilizado na construção de estruturas e grandes obras viárias. Seu emprego é conhecido em todo o mundo e seu uso é difundido pela facilidade de execução e adaptação as mais diferentes formas. No entanto a garantia de qualidade e segurança exige uma série de cuidados desde a fase de projeto até a execução.

Sendo o concreto armado um material não inerte, ele se sujeita a alterações ao longo do tempo, devido a interações entre seus elementos constitutivos (cimento, areia, brita, água e aço), interações entre esses e agentes externos (ácidos, bases, sais, gases e outros) e com materiais que lhe são adicionados (aditivos e adições minerais) [6].

Portanto, este trabalho trata de um estudo de caso realizado nas edificações pertencentes à Universidade Estadual Paulista (FCT/UNESP), campus de Presidente Prudente, em que por meio da realização de inspeção visual foram identificadas as manifestações patológicas existentes nas vigas e lajes de concreto armado. 


\section{Metodologia}

A apresentação das manifestações patológicas se limita ao estudo de caso, sendo que foram consideradas no trabalho as edificações localizadas na FCT/UNESP de Presidente Prudente. Os estudos de caso centraram-se nos elementos estruturais vigas e lajes. As análises se detiveram no estudo comparativo, vistas sob a ótica da sintomatologia.

Por meio de quadros (ou lâminas) se estudaram os tipos de danos com suas características, importância, as causas mais prováveis e as possíveis soluções de reparo, na qual são comentadas conforme o exemplo do Quadro 1. As referências que auxiliaram nessa etapa foram: Helene [7], Muñoz Hidalgo [8] e Souza e Ripper [2].

Quadro 1: Exemplo do conteúdo a ser apresentado no quadro sinóptico.

\begin{tabular}{|c|}
\hline $\begin{array}{l}\text { A) Figura } \\
\text { Apresenta-se uma figura especificando } 0 \text { tipo de } \\
\text { manifestação patológica. }\end{array}$ \\
\hline $\begin{array}{l}\text { B) Características } \\
\text { Especifíca-se as características da manifestação patológica, } \\
\text { indicando onde e como se inicia, sua progressão e como } \\
\text { finaliza antes de romper (caso possa ocorrer). Também se } \\
\text { indica detalhes e peculiaridades de cada tipo de manifestação } \\
\text { patológica. }\end{array}$ \\
\hline 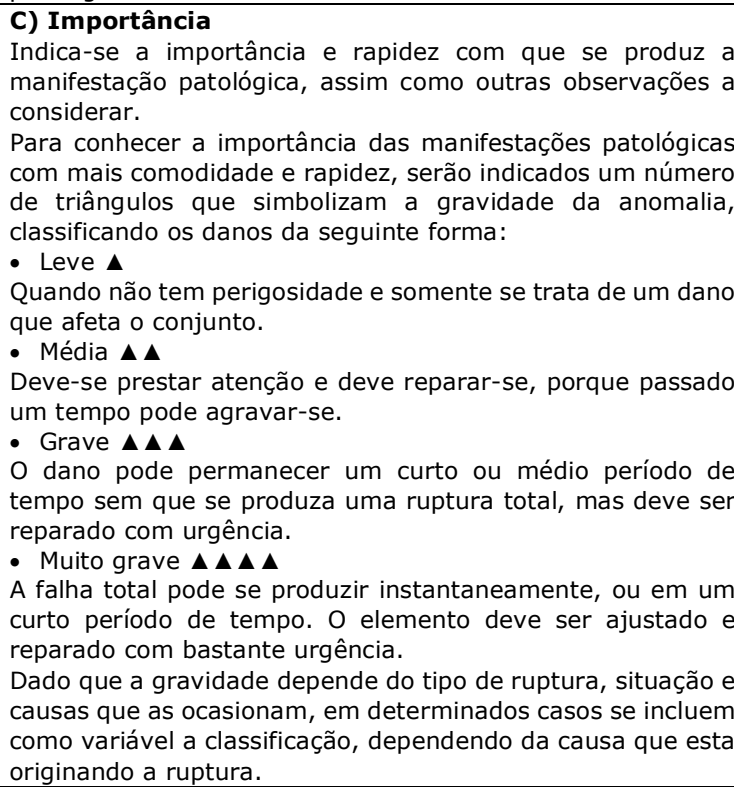 \\
\hline $\begin{array}{l}\text { D) Causas mais prováveis } \\
\text { Indicam-se as causas prováveis que originam o dano, que em } \\
\text { cada caso pode haver ocasionado uma ou várias, e quanto } \\
\text { maior seja seu número mais aumenta a gravidade. } \\
\text { Em determinados casos é difícil detectar as causas que } \\
\text { provocaram as falhas. Ante isso, é preferível seguir um } \\
\text { sistema de eliminação descartando as causas que temos } \\
\text { certeza que não ocasionaram o dano, e estudar em } \\
\text { profundidade as causas suspeitas que restaram. }\end{array}$ \\
\hline E) Possíveis soluções de reparo \\
\hline
\end{tabular}

Como cada dano geralmente tem diferentes soluções, dependendo das causas que ocasionaram, segue a orientação sobre as possíveis reparações.

Sempre que possível deve-se eliminar a causa que ocasionou o dano.

Na maioria dos casos os danos admitem diferentes soluções, variando bastante entre eles a dúvida de qual solução é a melhor.

Como orientações são apresentadas as condições que requerem cumprir uma solução para considerá-las mais idônea:

- A mais segura;

- A mais duradoura;

- A mais fácil de executar;

- Aquela em que os reforços não são visíveis:

- A que precisa menos mão de obra;

- Aquela que ocasiona menos moléstias e deterioração;

- A mais econômica.

Convém relatar que se cumpra com a maioria dos requisitos possíveis, reforçando com o mesmo material com que esta executada a estrutura (na medida do possível), já que materiais distintos podem apresentar diferentes comportamentos térmicos.

Fonte: Muñoz Hidalgo [8] - modificado.

\section{Resultados}

\subsection{Escolha das edificações}

O critério de escolha das edificações objeto de estudo partiu do quesito estrutural, ou seja, a definição do concreto armado como material constituinte do sistema estrutural e ter suas estruturas aparentes. Pois nestas condições seria possível identificar e analisar, a partir das vistorias e fotografias digitais, as eventuais manifestações patológicas.

A FCT/UNESP esta devidamente distribuída nos aproximadamente $400.000 \mathrm{~m}^{2}$ de área, e conta com mais de 33 edificações que se encontram localizadas em três partes: área norte, área central e área sul, cujas duas primeiras estão separadas pela Rua Roberto Simonsen, como mostra a Figura 1.

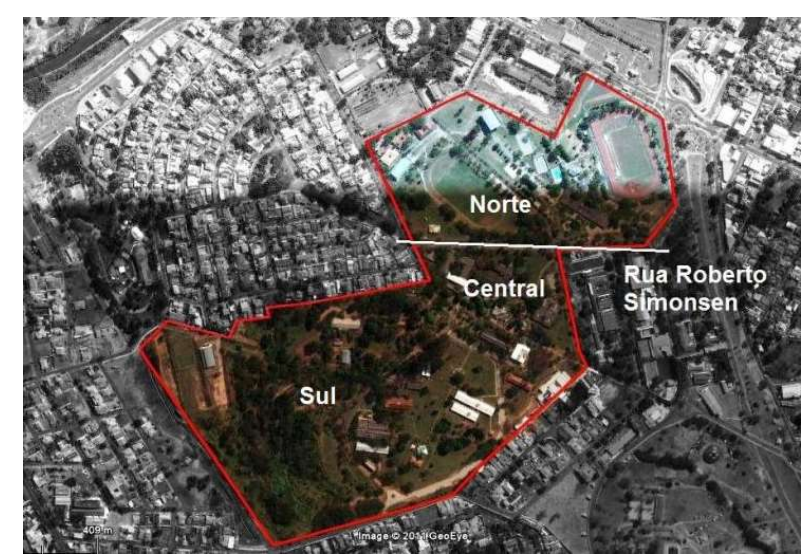

Figura 1: Delimitação da área da FCT/UNESP. Fonte: Autores (2017). 


\subsection{Manifestações patológicas identificadas}

Com base nos dados de campo, as manifestações patológicas mais evidentes nas vigas foram: manchas escuras, lixiviação, corrosão da armadura por esfoliação e corrosão de estribos. Nas lajes os principais problemas acometidos foram: recalque diferencial, fissuras de retração térmica e corrosão de armadura. $\mathrm{Na}$ sequência serão apresentados os Quadros 2 a 8, em que poderão ser observadas as anomalias estudadas.

Quadro 2: Manchas escuras em viga.

\begin{tabular}{l}
\hline Manchas escuras \\
\hline A) Figura \\
Face sombra \\
Idade do elemento estrutural na vistoria: 48 anos \\
Período da vistoria: Maio de 2017 Fanchas escuras, tanto na parte exposta como também na \\
parte coberta da viga, além da proliferação de microganismos \\
(cor verde) no local que coincide com a queda da água \\
pluvial, proveniente da telha de fibrocimento que constitui o \\
telhamento.
\end{tabular}

\section{B) Características}

As manchas superficiais de tonalidade escura ou mesmo esverdeadas, são decorrentes da proliferação de microrganismos ou surgimento de bolor, o que acaba por prejudicar a estética da edificação.

Em estruturas expostas às intempéries, na fase de uso da edificação, as manchas são provenientes principalmente de chuvas incidentes, de forma que o acúmulo ou escoamento de água na superfície ocorre em função dos seguintes fatores: projeto, condições climáticas, presença de defeitos superficiais, geometria e propriedades dos materiais.

\section{C) Importância}

Causa alteração estética do ambiente, formando manchas escuras indesejáveis. O mofo ou bolor é uma alteração observável macroscopicamente na superfície do concreto, sendo uma consequência do desenvolvimento de microrganismos pertencentes ao grupo dos fungos. Sendo um organismo vivo, os fungos têm seu desenvolvimento afetado pelas condições ambientais, sendo a umidade fundamental.

\section{D) Causas mais provável}

- Acúmulo de água e infiltrações;

- Alta permeabilidade do concreto;

- Fissuras na superfície do concreto favorecendo a entrada de água presente;

- Proliferação de fungos e bolores;

- Corrosão da armadura (manchas avermelhadas) por cobrimento deficiente:

- Percolação da água.

E) Possíveis soluções de reparo

- As machas escuras e esverdeadas causadas por fungos e bolores são mais fáceis de ser removidas utilizando uma lavadora de pressão e esfregando uma escova mais rígida com solução que contenha cloro;

- Para as manchas avermelhadas causadas pela corrosão das armaduras é necessário o uso de escova com solução ácida para eliminar a coloração impregnada;
- Para ambos os casos é necessário acabar com a entrada da água e umidade através de impermeabilizações e reparos em fissuras.

Fonte: Autores (2017).

Quadro 3: Lixiviação em vigas distintas.

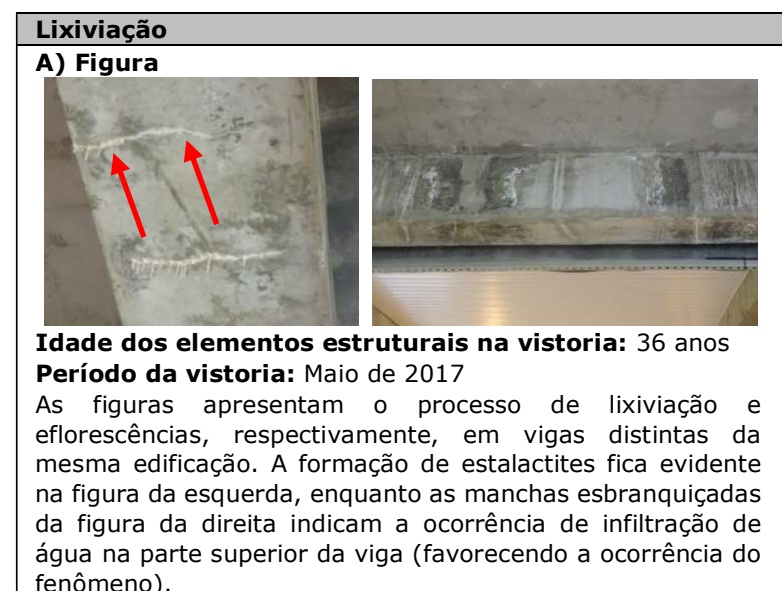
fenômeno).

\section{B) Características}

A lixiviação é a ação extrativa ou de dissolução que os compostos hidratados da pasta de cimento podem sofrer quando em contato com água, principalmente as puras ou ácidas.

A lixiviação do hidróxido de cálcio $\left[\mathrm{Ca}(\mathrm{OH})_{2}\right]$ com a consequente formação do carbonato de cálcio insolúvel, são responsáveis pelo aparecimento de eflorescências caracterizado por depósitos de cor branca na superfície do concreto, alterando a estética do elemento.

Fatores externos que contribuem: quantidade de água, tempo de contato, elevação de temperatura e porosidade do material.

O potencial hidrogeniônico $(\mathrm{pH})$ do concreto é diminuído, dando lugar à decomposição de outros hidratos, aumentando sua porosidade e facilitando a desintegração. Surgem como resultado da lixiviação as formações do tipo estalactites e estalagmites.

\section{C) Importância $\Delta \Delta / \Delta \Delta \Delta$}

A lixiviação é nociva ao concreto por várias razões: com a remoção de sólidos, ocorre redução na resistência mecânica do material e abre-se caminho para a entrada de gases e líquidos agressivos às armaduras e ao próprio concreto, além da penetração de água e oxigênio que normalmente redunda na corrosão de armaduras em peças de concreto armado ou concreto protendido.

\section{D) Causas mais provável}

- Excesso de umidade;

- Acúmulo de água e infiltrações;

- Alta permeabilidade do concreto;

- Fissuras na superfície do concreto favorecendo a entrada de água;

- Percolação da água;

- Dissolução e carreamento do hidróxido de cálcio existente no cimento por meio da ação da água;

- Migração e posterior evaporação de soluções aquosas salinizadas.

\section{E) Possíveis soluções de reparo}

- Remover as manchas e estalactites com lavagem à pressão e uso de escova com soluções ácidas;

- É necessário acabar com a entrada da água e umidade através de impermeabilizações e reparos em fissuras.

Fonte: Autores (2017). 
Quadro 4: Corrosão por esfoliação em vigas distintas.

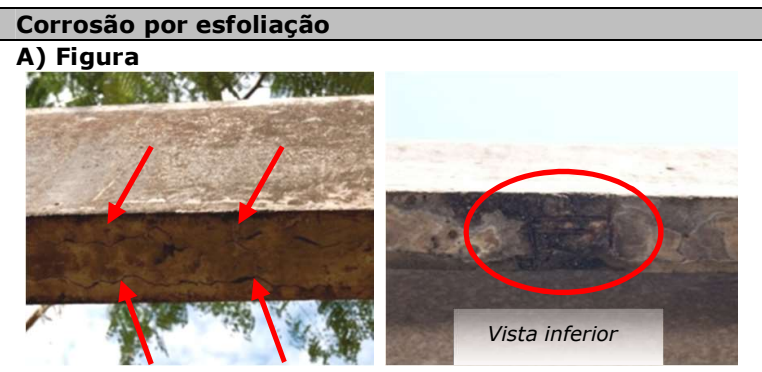

Idade dos elementos estruturais na vistoria: 38 anos

Período da vistoria: Abril de 2017

Na corrosão por esfoliação, ao aumentar tanto de volume, o aço fica sem espaço entre as barras propiciando o surgimento das fissuras longitudinais. Devido à agressividade e aumento do volume das barras, os estribos terminam se rompendo e desaparecendo por corrosão. Nas figuras são apresentados exemplos de corrosão por esfoliação em vigas distintas, expostas as intempéries.

\section{B) Características}

$\mathrm{Na}$ corrosão por esfoliação, a armadura se desprende em capas, aumentando aproximadamente de 5 a 6 vezes seu volume inicial e ficando totalmente inservível. Geralmente ocorre em elementos sem proteção situados em terrenos ou ambientes muito agressivos, e quando se utilizaram agregados muito contaminados.

Esta corrosão arruína rapidamente o elemento e ocasiona sua retirada, com exceção de que o elemento não tenha nenhuma missão resistente ou que a armadura se encontre muito bem ancorada permanecendo mais tempo.

Na corrosão por esfoliação ao desprender-se do aço em lascas temos que ter a precaução de não tocar nas barras, já que se incrustam nas mãos, no qual se supõe um grave risco para a saúde.

\section{C) Importância $\Delta \Delta \Delta$}

A corrosão é rápida e progressiva, aumentando sua rapidez em elementos muito tensionados e segundo a causa que ocasiona a corrosão.

Se não são tomadas medidas de urgência ao princípio de corrosão, dependendo do caso, ficará o elemento totalmente inutilizado.

\section{D) Causas mais provável}

- Empregar agregados muito contaminados;

- Atmosfera muito agressiva;

- Omissão de espaçadores na armadura.

\section{E) Possíveis soluções de reparo}

- Averiguar a causa que ocasiona a corrosão;

- Se a corrosão está muito avançada ou se foram utilizados agregados contaminados, é preferível substituir o elemento por outro;

- Se a corrosão está no começo, eliminar a causa que a origina e proceder como se fosse uma corrosão generalizada;

- Substituir a armadura por outra nova se a corrosão estiver muito avançada.

Fonte: Autores (2017).

Quadro 5: Corrosão de estribos em vigas distintas.

\begin{tabular}{|l|}
\hline Corrosão de estribos \\
\hline A) Figura
\end{tabular}

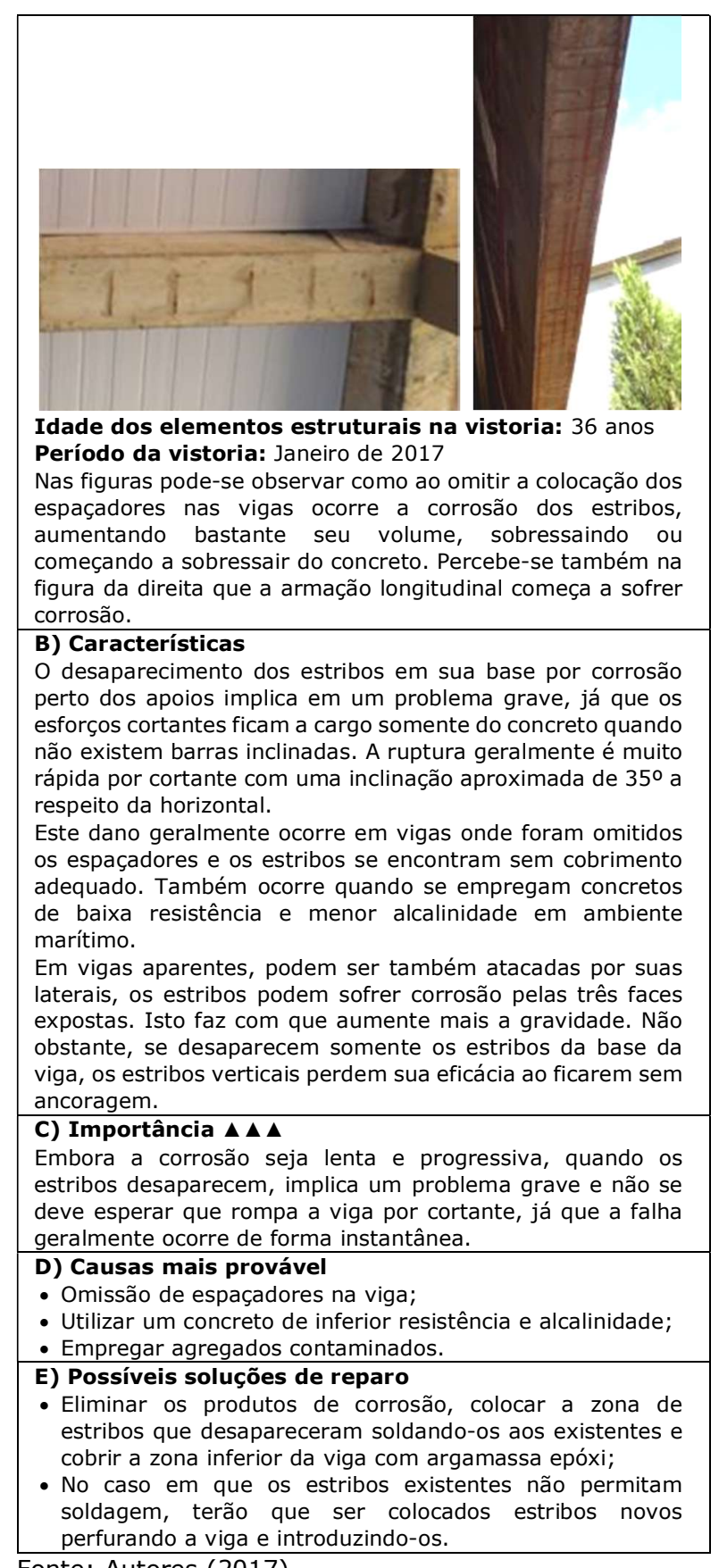

Fonte: Autores (2017).

Quadro 6: Recalque diferencial em laje.

Recalque diferencial

A) Figura 


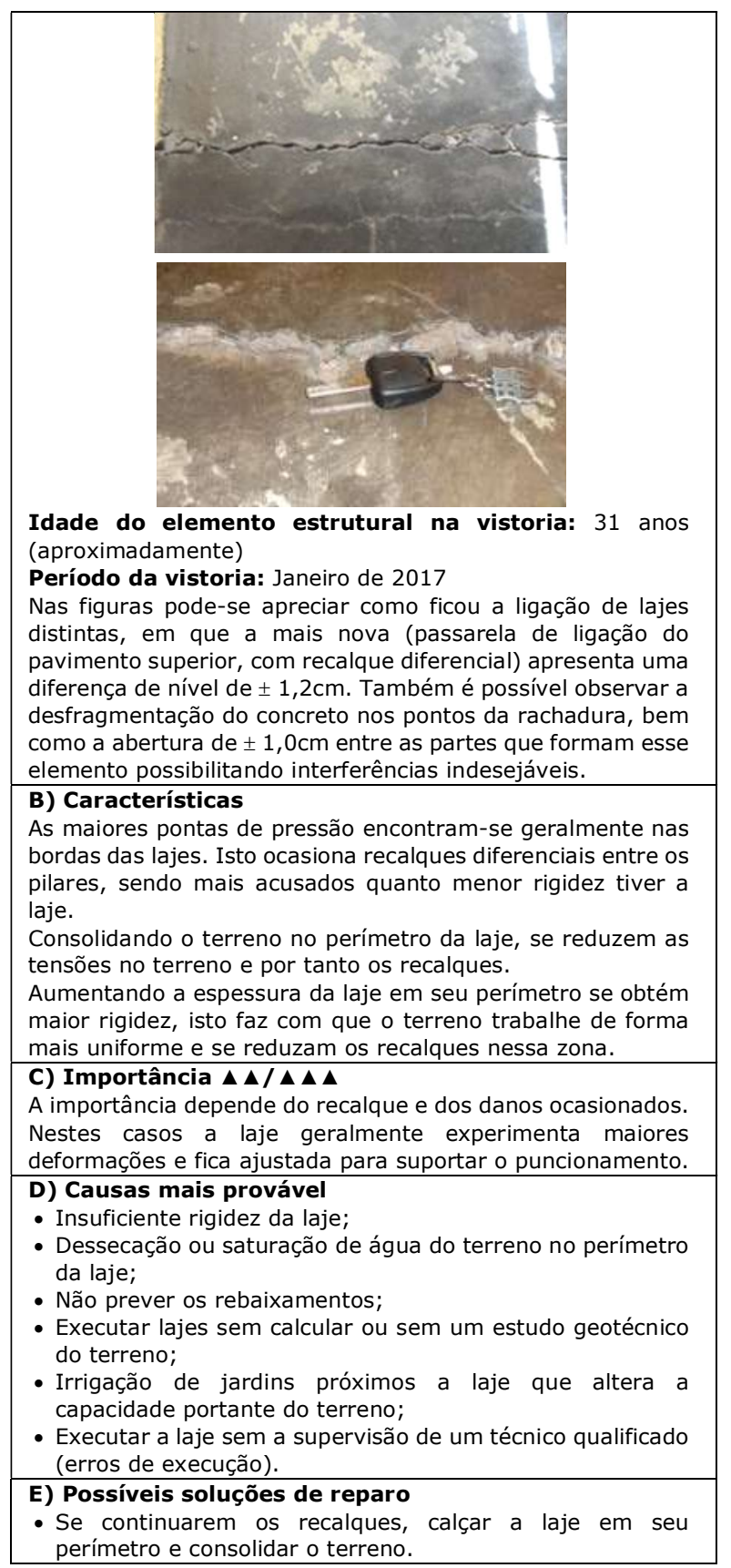

Fonte: Autores (2017).

Quadro 7: Fissuras de retração térmica em laje.

\begin{tabular}{|l|}
\hline Fissuras de retração térmica \\
\hline A) Figura \\
\hline
\end{tabular}

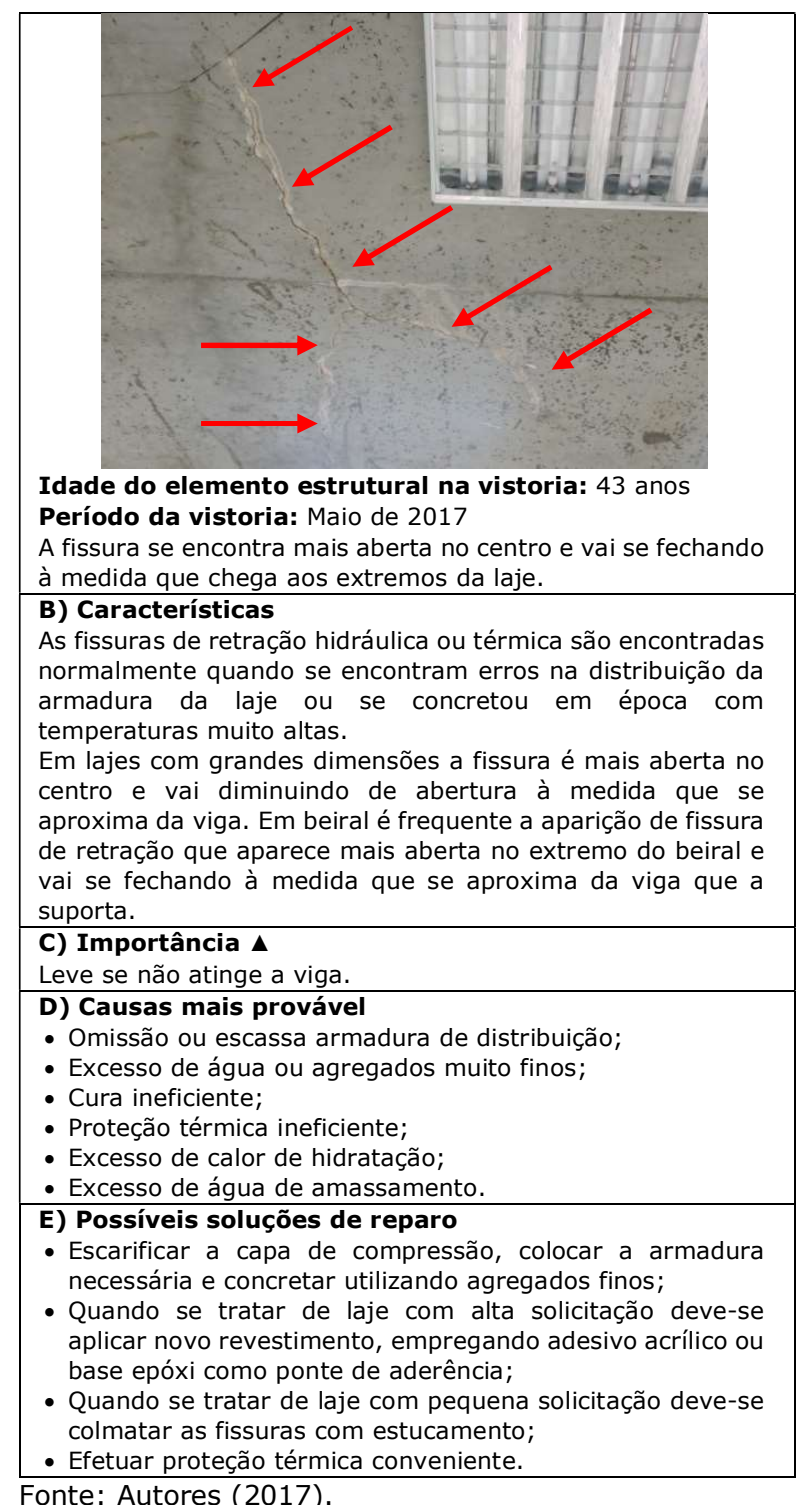

Quadro 8: Corrosão de armaduras em laje.

\begin{tabular}{|l|}
\hline Corrosão de armadura \\
\hline A) Figura \\
Idade do elemento estrutural na vistoria: 43 anos \\
Período da vistoria: Maio de 2017 \\
Na figuras aparecem as armaduras de lajes maciças em \\
processo de corrosão por umidade de condensação e também \\
pela falta de espaçadores. \\
\hline B) Características \\
A corrosão da armadura de uma laje normalmente ocorre \\
pela omissão de espaçadores. A corrosão ocorre também em \\
\hline
\end{tabular}


lajes de porão onde existe bastante umidade de condensação, bem como em lajes superiores de banheiros (edifícios de múltiplos pavimentos), pois o cloro da água favorece a corrosão.

A corrosão da armadura pode ocorrer quando em contato com o gesso que se aplica como revestimento inferior da laje. Nas lajes superiores de edifícios de múltiplos pavimentos podem existir forros de gesso, assim, devem-se fazer aberturas para observar se a armadura esta sofrendo corrosão por umidade de condensação.

\section{C) Importância $\Delta \Delta \Delta$}

A corrosão é lenta e progressiva. A falha ocorre por perda de aderência, porém antes que se produza, pode aparecer deformações na laje.

Nas corrosões generalizadas por esfoliação, a armadura se desprende ao desconectar-se do concreto.

D) Causas mais provável

- Armadura baixa por omissão de espaçadores;

- Umidade de condensação elevada;

- Concreto de baixa alcalinidade;

- Concreto muito poroso e pouco compacto;

- Má execução.

E) Possíveis soluções de reparo

- Eliminar a umidade de condensação;

- Eliminar a corrosão, aplicar uma pintura passiva e revestir com argamassa predosificada;

- Repor a seção da armadura que há desaparecido;

- Em casos de início de corrosão sem comprometimento do concreto e das barras de aço, recuperar o componente estrutural mantendo as dimensões originais através de: argamassa polimérica, argamassa epóxi, argamassa poliéster, eventualmente aplicar argamassa em todas as superfícies para aumentar o cobrimento e proteger o componente estrutural (atingindo a espessura mínima de cobrimento especificada na NBR 6118 (ABNT [9]);

- Em casos avançados de corrosão, reforçar o componente estrutural aumentando as dimensões originais através de reforço em: vigas, pilares e lajes;

- Aplicar revestimento de proteção

- Eventualmente, demolir ou reconstruir.

Fonte: Autores (2017).

\subsection{Análise geral}

Por meio das vistorias realizadas foi possível observar que as manifestações patológicas são diversas, e partem de fatores variados. Primeiramente, vale atentar ao fato de que parte dos elementos estudados (neste caso as vigas) estão expostas às intempéries, e com isso, a deterioração dos materiais que compõem o sistema estrutural reagem com os agentes externos e acarretam, muitas vezes, em anomalias. Portanto, é concebível considerar que estes fatores relacionados a um mau planejamento e/ou execução, acabam por acarretar as principais manifestações patológicas apresentadas no item 3.2.

Analisando os estudos de caso apresentados, pode ser observado um padrão apresentado no processo de recuperação das estruturas de concreto armado, no que diz respeito às técnicas de reparo das peças estruturais.
Após a apresentação das causas prováveis das manifestações patológicas, obtidas por meio de inspeção visual, pode ser notado que os procedimentos adotados nos casos estudados se assemelham. Execução da remoção da camada superficial do concreto, limpeza das armaduras com corrosão, proteção ou substituição das mesmas, recomposição do cobrimento das armaduras através de argamassa polimérica ou graute. Estas etapas são bastante difundidas entre os profissionais que trabalham em obra. O que pode diferenciar muitas vezes um serviço do outro é a qualidade dos materiais que são empregados, além do controle de execução das recuperações.

E se tratando de fissuras e corrosão das armaduras, podemos constatar que se não forem obedecidos os critérios para proteção e bom uso das estruturas, é certo que, necessariamente, em qualquer tempo, essa mesma estrutura precisará ser recuperada.

Diante do exposto, após a vistoria, estudo e diagnóstico das manifestações patológicas, a indicação do procedimento de correção deve levar em conta vários fatores como eficiência de intervenção, segurança, materiais, equipamentos, custo e condições específicas da obra, temperatura, prazos e agressividade do ambiente durante e após a correção.

Para cada tipo de problema patológico pode haver mais de uma solução e mais de um procedimento de correção, que será adotado em função de fatores técnicos e econômicos. A disponibilidade de tecnologia local deve sempre ser levada em conta, ou seja, a existência ou não de pessoal habilitado, os materiais e equipamentos existentes no local da obra.

Procedimentos que exigem equipamentos específicos, como o uso de concreto ou argamassa polimérica projetados, tem campo de aplicação quando se trata de correções de problemas em grande áreas e de forma repetitiva. Outros, aparentemente mais artesanais, podem ser adequados para locais em que não se permita poeira e ruídos excessivos ou quando se trata de correção pequena.

Cabe lembrar que a segurança e satisfação final do proprietário serão atendidas na medida em que haja uma fiscalização eficiente e controle de qualidade de todas as atividades envolvidas. É conveniente realizar ensaios de resistência, aderência, durabilidade dos materiais, além de procurar comprovação da eficácia de certos procedimentos, através de testemunhos, provas de carga, ultrassom, medidas de potenciais de corrosão e outros recursos de análise de estruturas de concreto acabadas. 


\section{Conclusões}

A partir do levantamento dos dados patológicos observados nas estruturas em concreto das edificações objeto de estudos de caso, foi concluído que as recomendações sugeridas pelas normas NBR 6118 (ABNT [9]) e CEB:1990 (CEB [10]) são procedentes e necessárias. Podemos citar como exemplos bem sucedidos a obrigação de se evitar o acúmulo de água proveniente de chuva ou de limpeza nas superfícies das estruturas; a atenção especial à qualidade e à espessura mínima do cobrimento; o detalhamento correto das armaduras, com atenção aos espaçamentos mínimos e máximos entre barras de aço necessárias, respectivamente para a concretagem dos elementos estruturais e para atender as necessidades de armadura para se evitarem fissuras nas regiões mais solicitadas à tração; e principalmente o cumprimento das manutenções preventivas e corretivas, estas quando necessárias. Isto possibilitou concluir que, na maioria das vezes, a ocorrência de uma dada anomalia poderia ter sido evitada se, na ocasião do seu projeto e construção, existissem os conhecimentos que estão hoje nas normas atuais citadas.

Por fim, deve ser ressaltado que os trabalhos de recuperação e reforço de estruturas devem ser executados com todo o cuidado, utilizando equipamentos específicos e mão de obra especializada, devendo existir uma fiscalização eficiente e controle da qualidade dos materiais e de todas as atividades envolvidas, para que se possa chegar a um resultado satisfatório.

\section{Referências}

[1] SANTOS, M. R G dos. Deterioração das estruturas de concreto armado - Estudo de caso. 2012. Monografia (Especialização em Construção Civil) - Escola de Engenharia da Universidade Federal de Minas gerais, Belo Horizonte.

[2] SOUZA, V. C. M.; RIPPER, T. Patologia, recuperação e reforço de estruturas de concreto. São Paulo: Editora Pini, 1998, 255p.

[3] TUTIKIAN, B.; PACHECO, M. Inspección, diagnóstico y prognóstico em la construcción civil. Boletín Técnico. ALCONPAT Internacional, Mérida, 2013.

[4] KLIMPEL, E. C.; SANTOS, P. R. C. Levantamento das manifestações patológicas presentes em unidades do conjunto habitacional Moradias Monteiro Lobato. 2010. 98f. Monografia
(Especialização em Patologia nas Obras Civis) Instituto IDD, Curitiba.

[5] SOARES, A. P. F.; VASCONCELOS, L. T.; NASCIMENTO, F. B. C. Corrosão em armaduras de concreto. Ciências Exatas e Tecnológicas, v.3, n.1, p.177-188, 2015.

[6] VITÓRIO, A. Fundamentos da patologia das estruturas nas perícias de engenharia. Instituto Pernambucano de Avaliação e Perícias de Engenharia. Recife, 2003.

[7] HELENE, P. R. L. Manual para reparo, reforço e proteção de estruturas de concreto. São Paulo: Editora Pini, 1992.

[8] MUNÕZ HIDALGO, M. Manual de patologia de la edificación (detección, diagnosis y soluciones). Pinto (Madrid), DÉDALO OFFSET, 2012.

[9] ASSOCIAÇÃO BRASILEIRA DE NORMAS TÉCNICAS (ABNT). NBR 6118: Projeto de estruturas de concreto - procedimentos. Rio de Janeiro, 2014.

[10] COMITÉ EURO-INTERNATIONAL DU BETON (CEB). CEB:1990: CEB-FIP Model Code 1990; final draft. Lausanne: CEB, 1991. 